\title{
Evaluation and analysis of the uncertainty measurement linear thermal expansion coefficient of ceramic brick
}

\author{
Hui Gao ${ }^{1 *}$, Zhengfa Yuan ${ }^{2}$, Ming Gong ${ }^{3}$, Wenjin Zhou ${ }^{1}$, Bo Zhong ${ }^{1}$, Kunli Duan ${ }^{1}$ \\ ${ }^{1}$ China building materials inspection and Certification Group Shaanxi Co., Ltd. Xi'an 710116, Shaanxi \\ ${ }^{2}$ Jiangxi Hemei Ceramic Company Limited, Feng Cheng 331117, Jiangxi \\ ${ }^{3}$ Quality Supervision and Inspection of Building and Sanitary Ceramics of Jiangxi Province, Gao An 330800, Jiangxi
}

\begin{abstract}
With the continuous and high-speed growth of economy, people's requirements on product quality are increasing year by year, including ceramic brick products, which, as a typical building materials product, are widely used in all kinds of buildings of different sizes. Quality of brick of pottery and porcelain products mainly in the form of through the examination and evaluation. The uncertainty of measurement as an important part of the test results, is an important parameter characterization of the reliability of the measurement result. Therefore, this paper, the source of uncertainty in linear thermal expansion coefficient measurement of ceramic brick is analyzed, using the measurement results and related data, and concludes that for the linear thermal expansion coefficient average of $0.016 \%$. when the report 2 sample average, the expanded uncertainty $\mathrm{U}(\mathrm{A})=1.48 \%$, contains the factor $\mathrm{k}=2$ ".
\end{abstract}

\section{Introduction}

At present, China has become the world's largest building sanitary ceramics manufacturing countries. According to statistics, 2019, the building ceramic industry above designated size 3079.91 main business income is one hundred million yuan RMB. The national 10.161 billion $\mathrm{m}^{2}$ brick of pottery and porcelain production. Quantitative change causes the qualitative change, qualitative change depends on the improvement of testing technology. The uncertainty of measurement is an important indicator of testing technology level. JJF1059.1-2012 "the uncertainty of measurement and said". It has made it clear that the final form with the uncertainty of measurement results for evaluation and said the uncertainty of measurement results is becoming more common. The study results of uncertainty evaluation of measurement results emerge in endlessly, has involves each aspect [1] - [3]. Therefore, this article takes a typical building materials product of brick of pottery and porcelain product as the research object, carry out side of brick of pottery and porcelain straight degree evaluation of uncertainty analysis.

\section{Brick of pottery and porcelain coefficient of linear thermal expansion measurement analysis}

According to the national standard GBT3810.8-2016 determination of linear thermal expansion instrument and calculate the coefficient of linear thermal expansion uncertainty generated by the testing process. According to the national standard GB/T 4100-2015, it has combined with decision rules on the use of edge straight degree of uncertainty, on the determination of edge straight numerical determine whether qualified.

\subsection{Measurement purposes}

Measurement of brick of pottery and porcelain sample from room temperature to $100{ }^{\circ} \mathrm{C}$ in the range of linear variation.

\subsection{Method of measurement}

In $110+5{ }^{\circ} \mathrm{C}$ drying oven drying to constant weight, both within $24 \mathrm{~h}$ weighing less than 0.1 the difference between the twice within the sample. It has put into the dryer to cool to room temperature.

Sample length is measured with vernier caliper, accurate to $0.1 \mathrm{~mm}$.

The sample in the thermal expansion instrument and record at this time in room temperature.

In the original and all the heating process, the determination of the length of the sample, accurate to 0.01 $\mathrm{mm}$.

Measure and record in no more than $15^{\circ} \mathrm{C}$ temperature and length value.

Heating rate $(5+1){ }^{\circ} \mathrm{C} / \mathrm{min}$.

Note: from the center of a brick vertically cut out two pieces of each sample, the sample length is suitable for testing instruments.

The ends of the specimen should be smooth and parallel to each other.

If necessary, any side length of sample cross section

*Corresponding author's e-mail: gaohui2020@aliyun.com 
should be ground to less than $6 \mathrm{~mm}$, cross-sectional area should be greater than $10 \mathrm{~mm}$ squared.

The minimum length of a sample of $50 \mathrm{~mm}$

The glair brick needn't wear off on the sample glaze.

\section{Measurement uncertainty analysis}

\subsection{The main source of uncertainty}

Random factors has affected edge straight degree of measuring results is more. It has come from the volatility measurement instrument and environment, the differences between the personnel operation, uneven factors such as the sample[4].

\subsection{The determination of uncertainty components}

\subsubsection{Repeatability of uncertainty components}

Repeated measurement 10 samples, measurement data in the following table 1. Bessel formula with a single measurement experiment standard deviation[5]:

Table1. The measured results

\begin{tabular}{|c|c|c|c|c|}
\hline $\begin{array}{c}\text { Measuring the serial } \\
\text { number }\end{array}$ & $\mathrm{L}_{\mathrm{U}}(\mathrm{mm})$ & $\mathrm{L}_{0}(\mathrm{~mm})$ & $\mathrm{L}_{\mathrm{U}}-\mathrm{L}_{0}(\mathrm{~mm})$ & $A_{i}(\%)$ \\
\hline 1 & 45.677 & 45.670 & 0.007 & 0.015 \\
\hline 2 & 45.898 & 45.890 & 0.008 & 0.017 \\
\hline 3 & 44.566 & 44.560 & 0.006 & 0.013 \\
\hline 4 & 45.467 & 45.460 & 0.007 & 0.015 \\
\hline 5 & 44.877 & 44.870 & 0.007 & 0.016 \\
\hline 6 & 45.536 & 45.530 & 0.006 & 0.013 \\
\hline 7 & 45.245 & 45.240 & 0.008 & 0.018 \\
\hline 8 & 45.776 & 45.770 & 0.008 & 0.017 \\
\hline 9 & 44.467 & 44.460 & 0.007 & 0.016 \\
\hline 10 & 44.798 & 44.790 & 0.008 & 0.018 \\
\hline The average & 45.231 & 45.224 & 0.007 & 0.016 \\
\hline $\begin{array}{c}\text { The standard } \\
\text { deviation }\end{array}$ & & & & 1.05 \\
\hline
\end{tabular}

$$
\mathrm{S}(\mathrm{A})=\sqrt{\frac{\sum_{i=1}^{10}(A i-\bar{A})}{10-1}}=1.05 \%
$$

Often report parallel measuring the average of the two samples, the average thermal expansion coefficient of the standard deviation is:

$$
\mathrm{S}(\bar{A})=\frac{S(A)}{\sqrt{2}}=0.74 \%
$$

The average of relative standard deviation is:

$$
\mathrm{u}_{\text {rel }}\left(\mathrm{f}_{\text {rep }}\right)=\frac{S(\bar{A})}{\bar{A}}=46.25 \%
$$

\subsubsection{Calibration uncertainty components}

Sample edge straight degree is measured with a dial indicator, the range of $0-150 \mathrm{~mm}$, limit error for $+/-0.02$ $\mathrm{mm}$, assumption of uniform distribution, the standard uncertainty of measuring calibration are as follows:

$$
\mathrm{u}\left(\mathrm{L}_{0}\right)=\frac{0.02}{\sqrt{3}}=0.0116 \mathrm{~mm}
$$

The relative standard uncertainty for:

$$
\mathrm{u}_{\mathrm{rel}}\left(\mathrm{L}_{0}\right)=\frac{0.0116}{0.016}=72.5 \%
$$




\subsubsection{Synthetic standard uncertainty}

Straight degree of synthesis standard uncertainty according to the following formula:

$$
\begin{aligned}
\mathrm{u}_{\mathrm{c}}(\mathrm{A}) & =\mathrm{A} \times \sqrt{u_{r e l}^{2}\left(L_{U}-L_{0}\right)+u_{r e l}^{2}\left(L_{0}\right)+u^{2}\left(f_{r e p}\right)} \\
& =0.016 \times \sqrt{0+0.0021^{2}+0.4625^{2}}=0.74 \%
\end{aligned}
$$

\subsubsection{The expanded uncertainty}

he expanded uncertainty $\mathrm{U}=\mathrm{k} \times \mathrm{u}_{\mathrm{c}}(\mathrm{A})=2 \times 0.74 \%=1.48 \%$, contains the factor $\mathrm{k}=2$

\subsubsection{The results reported}

Using the measurement results and related data, and concludes that for the linear thermal expansion coefficient average of $0.016 \%$, when the report 2 sample average, the expanded uncertainty $\mathrm{U}(\mathrm{A})=1.48 \%$, contains the factor $\mathrm{k}=2$

\section{Looking forward}

In this paper, the ceramic tile edge straight degree evaluation of uncertainty was analyzed, and the related conclusion. In the future, along with the advance of the sustainable development of economy, society, measurement uncertainty theory will be more and more attention, more uncertainty evaluation of new methods and new theory will be put forward constantly, widely used in various fields.

\section{Reference}

1. Li Lingmei, zhang jianhua, et al. Wooden straight (passbook) measurement uncertainty evaluation [J]. Journal of foreign electronic measurement technology, 2015 (4): 36-38.

2. LingMing, hui-min li, li shoulders, etc., including correlation of quasi monte carlo evaluation method of uncertainty in measurement [J]. Journal of instruments and meters, 2014, 5-13.

3. Ye Depei, zhao, ShiChangYan, etc., the measurement uncertainty evaluation and table [5]. Beijing: China metrology publishing house, 2012.

4. Duan Xianhu. Analysis Report on the Results of the National Supervision and Spot Check on the Quality of Ceramic Toilet Products in 2012 [J]. Ceramics, 2013(06):40-41.

5. State Administration for Market Regulation. The national supervision and random inspection of the quality of 38 kinds of products such as the restraint system for children of motor vehicles in 2019[Z]. 2020-01-22. 